\title{
Correction to: Systematic reporting to improve the emergency medical response to major incidents: a pilot study
}

Sophie Hardy ${ }^{1 *}$, Sabina Fattah ${ }^{2,3}$, Torben Wisborg ${ }^{3,4,5}$, Lasse Raatiniemi ${ }^{4,6,7}$, Trine Staff ${ }^{8}$ and Marius Rehn $n^{2,9,10}$

\section{Erratum}

The original article [1] contains an error whereby all authors' names were mistakenly interchanged. The original article has now been corrected to present the authors' names correctly.

In addition, this error was mistakenly carried forward by the production team that handled the article, and as such, was not the fault of the authors.

\footnotetext{
Author details

${ }^{1}$ Emergency Department, St George's Hospital, Tooting, London, UK. ${ }^{2}$ The Norwegian Air Ambulance Foundation, Drøbak, Norway. ${ }^{3}$ Anaesthesia and Critical Care Research Group, Faculty of Health Sciences, University of Troms $\varnothing$, Tromsø, Norway. ${ }^{4}$ Hammerfest Hospital, Department of, Anaesthesiology and Intensive Care, Finnmark Health Trust, Hammerfest, Norway. ${ }^{5}$ Norwegian National Advisory Unit on Trauma, Division of Emergencies and Critical Care, Oslo University Hospital, Oslo, Norway. ${ }^{6}$ Centre for Pre-Hospital Emergency Care/ FinnHEMS 50, Oulu University Hospital, Oulu, Finland. ${ }^{7}$ Anaesthesia Research Group, MRC, University of Oulu, Oulu, Finland. ${ }^{8}$ Paramedic Sciences, Oslo and Akershus University College, Oslo, Norway. ${ }^{9}$ Department of Health Studies, University of Stavanger, Stavanger, Norway. ${ }^{10}$ Division of Emergencies and Critical Care. Department of Anaesthesia, Oslo University Hospital, Oslo, Norway.
}

Received: 1 February 2018 Accepted: 1 February 2018 Published online: 09 February 2018

\section{Reference}

1. Hardy $\mathrm{S}$, et al. Systematic reporting to improve the emergency medical response to major incidents: a pilot study. BMC Emerg Med. 2018;18:4.

* Correspondence: sophiehardy50@doctors.org.uk

'Emergency Department, St George's Hospital, Tooting, London, UK

Full list of author information is available at the end of the article 